Competition is becoming a permanent feature of the European research landscape, and local prestige, combined with local publications, may no longer suffice in the race for resources (both national and international) and wider academic recognition. Huge cross-disciplinary and crossnational differences apply, but, in general, the role of internationalization of research in European universities is greatly increasing.

\section{Ensuring Equality in Higher Education Partnerships In- volving Unequal Universities in Divergent Contexts}

\section{Cornelius Hagenmeier}

Cornelius Hagenmeier is Director of International Relations at the University of Venda, South Africa. E-mail: chagenmeier@gmail.com, cornelius.hagenmeier@univen.ac.za.

\begin{abstract}
A collaborative approach to internationalization through international partnerships is widely practiced and considered essential for higher education. However, the theoretical underpinnings of university partnerships have yet to be fully analysed and understood. The Nelson Mandela Bay Declaration on the Future of Internationalization (20I4) proclaims that the future agenda for internationalization should concentrate on "gaining commitment on a global basis to equal and ethical higher education partnerships."
\end{abstract}

\section{Equality in Partnerships}

While equality is commonly cited as a core principle underlying higher education partnerships, the doctrine is not yet clearly defined and the academic discourse on developing suitable concepts and strategies to achieve it is in its infancy. Inequalities are inherent to many higher education partnerships, and especially to those between universities of unequal strength. Inequalities are especially apparent when finance is provided by external donors, who may often be located in the context of the "stronger" university and who award funding exclusively to this partner because they share the same context.

\section{FORMAL EQUALITY}

Generally, recourse is made to a formal conception of equality in higher education partnerships, based on that aspect of Aristotelian understanding of equality which espouses that "things that are alike should be treated alike." This works well and achieves equitable results in instances where equality is to be accomplished between entities that are similar in their core characteristics, but has limitations with regard to realizing equality between entities with dissimilar features.

In higher education partnerships in which one partner makes a larger financial contribution than the other, pursuant to its superior economic strength, the stronger partner's influence on partnership decision-making processes is likely to be weightier. This dynamic is at times used by universities to secure a competitive advantage, especially when the partners are universities that vary greatly in size, shape, research output, reputation, and economic strength. The absence of formal equality poses a threat to the success and sustainability of partnerships and can result in the dominance of one partner to the relationship over the other. The prevalent influence of the dominant, economically stronger partner on the decision-making processes in a partnership is often justified by reference to larger financial contributions.

\section{While equality is commonly cited as a core principle underlying higher educa- tion partnerships, the doctrine is not yet clearly defined and the academic dis- course on developing suitable concepts and strategies to achieve it is in its in- fancy.}

\section{Substantive Equality}

A consensus exists that higher education partnerships should be equal or at least equitable, but it remains to be determined how this can be achieved in a global landscape characterized by unequal resources and divergent strengths of universities and higher education systems. As demonstrated above, formal equality is problematic as a conceptual basis for equality in higher education partnerships. It is necessary to interrogate whether equality should not be defined differently, for example by using an understanding that emphasizes the second element of the Aristotelian conception of equality-namely that "things that are unalike should be treated unalike in proportion to their unalikeness." A substantive conception of equality based on this 
principle has been widely used in human rights, labor, and gender discourses. It provides for the unequal treatment of fundamentally different cases and may be used in the higher education context to avoid the inequitable tendencies alluded to above.

A substantive understanding of equality in partnerships could provide a suitable theoretical framework to achieve the equitable sharing of the benefits of joint endeavors and consequently lead to real equality in partnerships. Such an understanding would reflect the differences between the entities involved in the relationship and provide a framework which acknowledges that diversity can serve as the foundation for equitable governance structures for partnerships. It considers that the nature and quantity of contributions to partnerships should depend on the individual partner's respective strength, but that the relationship should remain reciprocal.

To create certainty and promote equity, it would be desirable to adopt a conception of equality that clearly defines the extent of contributions required by partners. A useful example for the application of the principle of substantive equality is the 2013 internationalization policy of the University of Venda in South Africa, which adopts a substantive understanding of equality and defines it to mean that "every partner to a relationship should make contributions which are equally meaningful taking the context of the partner into consideration."

\section{CONCLUSION}

To counter inequalities and even exploitative undercurrents, which characterize many contemporary higher education partnerships, it is necessary to develop a theoretically sound conception of equality in alliances between universities of divergent strength, which goes beyond formal equality and rather looks at substantive equality. Further research will be required to gain a deep understanding of the present paradigm, which could serve to appropriately conceptualize a model that can advance genuine equality in higher education partnerships. It appears, prima facie, that the adoption of a substantive understanding of equality may facilitate the development of an equitable paradigm, which would ensure that genuine equality can be achieved in mutually beneficial and reciprocal higher education partnerships.

\section{Internationalization, the Cur- riculum, and the Disciplines}

\section{Hans de Wit and Betty Leask}

Hans de Wit is Director of the Center for International Higher Education (CIHE) at Boston College. E-mail: dewitj@bc.edu. Betty Leask is Pro Vice-Chancellor Teaching and Learning, La Trobe University, Melbourne, Australia. E-mail: B.Leask@latrobe.edu.au.This contribution is based on our Foreword for Wendy Green and Craig Whitsed. 2015. Critical Perspectives on Internationalising the Curriculum in Disciplines. Sense Publishers, Dordrecht.

T $\mathrm{n}$ the last decade, institutions of higher education, nation1 al governments, and (inter)national organizations have become more proactive, comprehensive, diverse, and innovative in their approaches to internationalization. Critical reflection on their outcomes-in particular their impact on student learning-has resulted in a search for approaches to internationalization that have deeper meaning and greater impact.

The search for new approaches is evident in the increasing use of terms such as "deep internationalization," "transformative internationalization," and "comprehensive internationalization." While such terms are increasing in number and frequently used, the challenge is to align rhetoric with practice. These terms are consistent with using internationalization as a driver of quality and innovation and reflect growing interest in ensuring the majority of students and staff are engaged in and changed by the internationalization agenda. They also have the potential to stimulate the development of approaches that address existing inequalities in educational opportunity and outcomes in the world today. Haphazard approaches to internationalization that focused on a minority of students or on profit rather than education are not consistent with such terms and insufficient in universities operating in a globalized world. In this super-complex world, multiple dimensions of being are required of both individuals and institutions. In this world, coherent and connected approaches to international education, which address epistemological, praxis, and ontological elements of all students' development, are urgently needed. Focusing attention on these goals has the capacity to transform an institution's approach to internationalization and the identity of the institution.

The curriculum is the vehicle by which the development of epistemological, praxis, and ontological elements can be incorporated into the life and learning of today's students, ensuring that they graduate ready and willing to make a positive difference in the world of tomorrow. Recently, questions related to the relationship between the in- 